\title{
Article \\ The Canadian Criminal Code Offence of Trafficking in Persons: Challenges from the Field and within the Law
}

\author{
Julie Kaye ${ }^{1, *}$ and Bethany Hastie ${ }^{2}$ \\ ${ }^{1}$ Department of Sociology, The King's University, Alberta, T6B 2H3, Canada; E-Mail: julie.kaye@kingsu.ca; \\ Tel: +1-780-465-3500 (ext. 8139); Fax: +1-780-465-3534 \\ ${ }^{2}$ Institute of Comparative Law, McGill University; Montréal, Québec, H3A 0G4, Canada; \\ E-Mail: bethany.hastie@mail.mcgill.ca \\ * Corresponding author
}

Submitted: 1 September 2014 | In Revised Form: 1 December 2014 | Accepted: 3 December 2014 |

Published: 23 February 2015

\begin{abstract}
Despite early ratification of the United Nations Trafficking in Persons Protocol, the Criminal Code offence of trafficking in persons in Canada has received little analytical or interpretive attention to date. Adopted in 2005, this offence has resulted in successful convictions in a limited number of cases and criminal justice authorities have continued to rely on alternate or complementary charges in cases of human trafficking. In particular, prosecutions for cases involving non-sexual labour trafficking remain extremely low. This article provides a socio-legal examination of why the offence of trafficking in persons in Canada is under-utilized in labour trafficking cases. Based on an analysis of data generated from 56 one-on-one interviews gathered from a variety of actors involved in counter trafficking response mechanisms and a legal examination of the key components of the offence, we argue that definitional challenges have resulted in narrow understandings and problematic interpretations of the Criminal Code offence. Such narrow interpretations have resulted in restricted applicability, particularly in cases of labour trafficking. More broadly, the article points to the need to address the limitations of the Criminal Code while formulating responses to trafficking that are not dependent on criminal law.
\end{abstract}

\section{Keywords}

Canadian Criminal Code; criminal justice; human rights; human trafficking; labour trafficking; law

\section{Issue}

This article is part of the special issue "Perspectives on Human Trafficking and Modern Forms of Slavery", edited by Siddharth Kara (Harvard Kennedy School of Government, USA).

(C) 2015 by the authors; licensee Cogitatio (Lisbon, Portugal). This article is licensed under a Creative Commons Attribution 4.0 International License (CC BY).

\section{Introduction}

Highly politicized and polarized discussions leading to the adoption of the international definition of human trafficking has resulted in a contested framework for understanding human trafficking in national contexts (Doezema, 2010; Gallagher, 2010; Hua, 2011; Jordan, 2002a; Kempadoo, 2005). In particular, the United Nations Protocol to Prevent, Suppress and Punish Trafficking in Persons, Especially Women and Children (hereaf- ter, the Protocol) has been co-opted to reinforce existing international debates regarding the disputed relationship between prostitution and the sexual exploitation of women and girls, with some groups engaged in the debates conflating human trafficking, sexual exploitation, and sex work (Doezema, 2002; Hua \& Nigorizawa, 2010; Sanghera, 2005; Soderlund, 2005; Thorbek \& Pattanaik, 2002). These debates, and the problematic discursive conflation between human trafficking and sex work, has impacted the resulting im- 
plementation of laws at the domestic state level, limiting not only the advancement of provisions to protect the rights of individuals working in sex industries (Chapkis, 2004; Doezema, 2010; Hua, 2011; Jordan, 2002b; Sanghera, 2005; Soderlund, 2005), but also the implementation of measures that address other forms of exploitation ${ }^{1}$ falling within the broader rubric of human trafficking, including forced labour, debt bondage, and domestic servitude. While some states, including the United States (William Wilberforce Trafficking Victims Protection Reauthorization Act 2008), and more recently the United Kingdom (Coroners and Justice Act 2009) and Australia (Crimes Legislation Amendment (Slavery, Slavery like Conditions and People Trafficking) Act 2013), have identified and addressed forced labour as a specific criminal offence within, or outside of, broader anti-trafficking legislation, Canada relies on a "catch-all" trafficking offence that does not delineate specific forms of exploitation. As a result, this article reveals the language of the criminal offence of trafficking in persons in Canada is largely unattuned to the phenomenon of non-sexual forms of labour trafficking. In turn, criminal justice authorities perceive significant difficulty in applying the offence to situations of non-sexual labour trafficking. More broadly, the article underscores the limitations of using a criminal law framework to address trafficking in persons, in general, and labour exploitation, in particular.

The Protocol was ratified by Canada through the inclusion of human trafficking offences in the Immigration and Refugee Protection Act [IRPA] (s.118) in 2002 and the Canadian Criminal Code (ss.279.01-.04) ${ }^{2}$ in 2005. Despite significant public attention to the issue of human trafficking, the Criminal Code offence has received little analytical or interpretive attention. ${ }^{3}$ To date, approximately a dozen convictions have

\footnotetext{
${ }^{1}$ While exploitation remains a contested term and language in general remains problematic in trafficking studies, we distinguish between sex trafficking and other forms of labour trafficking. Further, we recognize that not all forms of sexual labour are exploitative; however, human trafficking, by nature, requires exploitation to occur. Similarly, we also adopt the legal language of "victim" used in the criminal justice system for the purpose of situating this discussion within a criminal law framework. However, we recognize that "victim" and "exploited" labels have been used in anti-trafficking discourses to undermine the agency of individuals in a variety of areas, particularly sex trade industries where "victim status" is frequently rejected (Downe, 2006, p. 66; Sonderlund, 2005). Thus, our use of the term "victim" should not be understood as implicit support of enforcement-based approaches that deem voluntary forms of labour and migration as "exploitative" and operate to marginalize the voices and experiences of individual agency. Rather, we employ the label for practical purposes of examining the existing Criminal Code offence and its applicability to instances of non-sexual labour trafficking.

${ }^{2}$ Amended by SC 2005, c43; SC 2010, c3; SC 2012, c15.

${ }^{3}$ For a critical examination of Canadian trafficking legislation
}

been obtained under sections 279.01 and 279.04 (Royal Canadian Mounted Police [RCMP], 2013; United Nations Office on Drugs and Crime [UNODC], 2013; US State Department, 2010; US State Department, 2011; US State Department, 2012); ${ }^{4}$ of the few cases that have proceeded to trial, only one has produced a written decision that included substantial judicial consideration of the wording of the offence ( $R$. $v$. Urizar). All but one of the existing convictions involved sex trafficking, which points to a potential gap in the applicability of the legal framework to labour trafficking cases. ${ }^{5}$ Although it is possible this discrepancy can be accounted for by there simply being less labour-related cases, ${ }^{6}$ this article will demonstrate that law enforcement and social service providers in Canada perceive the Criminal Code to be less applicable in labour trafficking instances. This is especially problematic since there are few alternate charges available for cases of labour trafficking under the Criminal Code. ${ }^{7}$ As a result, the labour trafficking offence remains under-utilized.

Through an interdisciplinary analysis, this article provides a socio-legal examination of the Criminal Code trafficking in persons offence and how it is perceived by criminal justice and service provider representatives. Specifically, alongside a legal analysis of the key components of the Criminal Code offence, this article examines data generated from 56 one-on-one interviews (16 in Calgary, Alberta; 21 in Vancouver,

in relation to the procurement offence see Roots (2013).

${ }^{4}$ Of the stated 50 cases where human trafficking or related convictions have been obtained (see RCMP, 2013), only 10 reported cases of specific convictions under s.279.01 of the Criminal Code are known: $R$ v. Nakpangi 2008 (guilty plea); $R$ v. St Vil, [2008] OJ No 6023 (QL) (guilty plea); R v. Urizar 2010, (upheld on appeal, 2013 QCCA 46) (verdict by judge); $R$ v. Estrella 2011 (verdict by jury); $R$ v. AA 2012 (upheld on appeal, [2013] OJ No 3192 (QL)) (verdict by jury); R v. Byron 2013 (verdict by judge); $R$ v. Domotor 2012 (guilty plea); Emerson (see RCMP, 2010, p.25, guilty plea); Vilutis (see RCMP 2010, p. 25, guilty plea); Lennox (see RCMP 2010, p. 26, guilty plea). ${ }^{5} R \mathrm{v}$. Domotor represents a case of labour trafficking in which several accused pled guilty to charges, including of human trafficking under s.279.01 of the Criminal Code. Despite other possible identified cases of labour trafficking (See, i.e., Alberta Police Report, 2012; Brazao, 2008; LaJoie, 2011; Sikka, 2013), criminal charges under either the Criminal Code or $I R$ $P A$ offences of human trafficking have been relatively rare.

${ }^{6}$ Feingold (2005) argues that labour trafficking is likely more prevalent than trafficking for forced prostitution.

7 Complementary charges under the Criminal Code could include, for example: extortion (s.346); intimidation (s.423); or, kidnapping (s.279). No cases for labour trafficking prosecuted under alternate charges are known or available in official records. Conversely, in cases of sex trafficking, criminal justice authorities in Canada rely on alternate charges under the existing framework of offences in relation to prostitution: see Criminal Code of Canada, RSC 1985, c-C46, as amended by the Protection of Communities and Exploited Persons Act, SC 2014, c25. 
British Columbia; and 19 in Winnipeg, Manitoba $)^{8}$ with representatives involved in counter-trafficking related employment, including frontline workers, government officials, and law enforcement (see Appendix A for a list of selected government and nongovernment agencies represented by participants in one-on-one interviews)..$^{9}$ The interviews took the form of face-to-face or, when not possible, over-the-phone conversations and involved open-ended discussions (see Appendix B for a list of questions used to guide the interviews). ${ }^{10}$ Using content analysis, the interview data was examined for recurring and/or significant themes and compared these themes with the findings of the legal examination of the criminal offence. ${ }^{11}$

${ }^{8}$ These cities were selected because they have been identified as "hot spots" of human trafficking (Oxman-Martinez, Lacroix, \& Hanley, 2005, p. 4). Further, Alberta and British Columbia represent two of three provinces where charges of labour trafficking have been laid in Canada (Public Safety Canada, 2012).

${ }^{9}$ The participants in this study represent a variety of perceptions within the counter-trafficking field, such as harm reduction and intervention strategies as well as various locations within criminal justice responses (e.g., immigration and passport sections, labour standards, city police involved in trafficking cases, legal representatives, etc.). Since their participation was based on their position within an institution of employment, participants from a variety of agencies were contacted directly, provided information about the study, and requested to contact the researcher if they would like to participate. They were asked questions based on their occupational knowledge. All participants were 18 years of age or older and there was no remuneration or compensation offered to those who participated in the study. Consequently, potential participants did not feel coerced or obligated to participate. In order to maintain the confidentiality of participants, the particular occupational positions held by participants has been omitted; however, the names of the type of organizations they represent have been included, except when participants requested otherwise (see Appendix A).

10 The principle investigator in this study, Dr. Julie Kaye, conducted the qualitative interviews. The interviews occurred between October 2010 and February 2011. All the interviews were conducted in English and ranged from 30 minutes to 2 hours in duration, but the majority of the interviews were approximately an hour in length. In all but a few instances, the interviews were audio recorded, transcribed verbatim, and then analyzed. A few participants did not consent to having the interview audio-recorded. In these instances, detailed notes were taken and analyzed.

11 An examination of recurrent and/or significant themes remains sensitive to both manifest content (e.g., assessing the frequency of specific recurring words, such as consent, victims, etc.) and latent content (e.g., assessing the overarching occurrence of themes, such as trafficked persons being portrayed in terms of their victimization, innocence, or resilience). However, rather than presupposing specific concepts or categories, this research approaches the data with an open, qualitative lens to uncover the thoughts, ideas, and meanings of the research participants (Strauss \& Corbin, 1998). Since this project is concerned with the depth and nuances necessary to understand a
The following section provides an overview of known labour trafficking trends and cases in Canada to date, and establishes the problem of under-recognition and underrepresentation of labour trafficking in Canadian law and policy. The third section introduces the Criminal Code offence and outlines the challenges of implementation perceived by law enforcement authorities, alongside problems of interpretation, including the role of movement and the challenges associated with the definition of exploitation. In particular, this section provides a legal analysis of the "fear of safety" standard, which has proven to be a key impediment to advancing criminal charges of labour trafficking. The fourth section examines the evidentiary burdens that further limit the use of the legislation, focusing on the problems presented by an emphasis on victim cooperation and credibility. The article concludes with a discussion of the limitations of the existing legislation and the associated insecurities these limitations create for trafficked persons in Canada.

\section{Labour Trafficking in Canada}

Before discussing the evidence of labour trafficking in Canada, it is necessary to clarify the relationship between various legal definitions at both the international and domestic levels. The international Protocol defines human trafficking as including three primary elements: an act (recruitment, transportation, transfer, harbouring or receipt); a means (threat or use of force or other forms of coercion, abduction, fraud, deception, abuse of power or of a position of vulnerability, or the giving or receiving of payments or benefits); and, a purpose of exploitation (the exploitation of the prostitution of others or other forms of sexual exploitation, forced labour or services, slavery or practices similar to slavery, servitude or the removal of organs). The Protocol thus makes explicit room for non-sexual forms of exploitation, specifically for forced labour, slavery or practices similar to slavery, and servitude. Background documents further suggest that these concepts should be interpreted in light of their existing definitions under international law. While a full canvassing of the particular definitions and interpretations of these related concepts is beyond the scope of this article, it is helpful to note that the definition of forced labour, particularly, is very broad in nature and encompasses a wide range of non-violent or non-physical coercive tactics. ${ }^{12}$ As such,

diverse range of experiences, such an approach uncovers how participants represent human trafficking and anti-trafficking initiatives and policies.

12 The definition of forced labour is found under the Convention Concerning Forced or Compulsory Labour (International Labour Organization, 1932, art 2(1)): “all work or service which is exacted from any person under the menace of any penalty and for which the said person has not offered himself voluntarily". Although there are many links to be made between the 
this article employs the term "labour trafficking" in a broad manner, consistent with possible interpretations at the international level. However, the manner in which domestic legislation accounts for the various elements under the Protocol ranges greatly and, as will be seen in section 3 , the definition of human trafficking under Canadian criminal law is critiqued for its narrow interpretation in this regard.

In implementing the Protocol in domestic legislation, Canada adopted two primary offences under IRPA and the Criminal Code. The IRPA offence is focused on organizing entry into Canada, and does not explicitly include a requirement that an individual was exploited, only that their entry was facilitated through "abduction, fraud, deception or use or threat of force or coercion" (s.118, IRPA). Thus, where the IRPA offence is applicable, its elements are generally straightforward and clear in their interpretation (see $R v . N g, R v$. Ladha which set out the elements of the offence and their interpretation). However, the IRPA offence is limited in its applicability to only one possible population of trafficked persons: foreign nationals who have been brought into Canada through unauthorized means. Where a foreign national was brought to Canada through legitimate means, and later exploited, such as individuals arriving under the Temporary Foreign Workers Program (where specific concerns have arisen in relation to labour trafficking, see RCMP, 2010; Sikka, 2013; Hastie, 2012), the IRPA offence will likely be of limited use. Unlike the offence under IRPA, the offence under the Criminal Code focuses most significantly on the presence of exploitation of an individual, and is not limited to the crossing of international borders, or to foreign nationals (as will be discussed in Section 3). Thus, while the Criminal Code may have broader application in respect of the geographic and relational boundaries of its application, its focus on exploitation, and how that is defined and interpreted, is much more onerous than the IRPA offence.

Despite the low number of identified and prosecuted cases of labour trafficking, as outlined in the Introduction, evidence establishes that this form of human trafficking does exist within Canada. The available data on the issuance of Temporary Resident Permits (TRPs) for trafficked persons provide strong evidence to counteract the assertion that labour trafficking is relatively rare in Canada. Available statistics establish that, for the period from May 2006 to De-

concepts of forced labour and human trafficking as interrelated, but independent phenomenon (see, i.e., Gallagher, 2010 , p. 35, n. 95), discussions of this relationship are beyond the scope of this paper. Rather, this paper is focused on the legal definition of human trafficking and its operationalization in contexts of non-sexual forms of labour, as discussed in the introduction to this article. As such, it is the components and features of the legal definition of "human trafficking" at both international and domestic levels, and its interpretations, that are central to the arguments put forth in this article. cember 2012, Citizenship and Immigration Canada (CIC) issued TRPs to 89 foreign nationals, 64 (72\%) of which were identified as "victims of trafficking for labour exploitation" (Public Safety Canada, 2013). Thus, a significant majority of potentially trafficked persons, as determined by $\mathrm{CIC}$, were subjected to labour trafficking, not sex trafficking, which is identified separately. Moreover, this occurs in a context where frontline workers identify that accessing TRPs for individuals victimized by labour trafficking has proven particularly challenging (see Kaye, Winterdyk, \& Quarterman, 2013). In addition to CIC data, a recent study commissioned by Public Safety Canada identified 47 possible cases of trafficking for labour exploitation (Sikka, 2013, see Annex A at pp. 39-47).

However, despite this evidence, a pervasive belief concerning the dominant, if not singular, presence of human trafficking as sexual exploitation has relegated the issue of labour trafficking to the background of both policy and on-the-ground action. As one law enforcement representative in British Columbia describes:

We haven't here done any big [labour trafficking] investigations. I've got to be quite frank with you. I put a much greater value on the female victims of human trafficking in the sex trade. Twenty men from Mexico or Africa who are forced against their will to work under horrible conditions is very, very bad, but you know their lives probably aren't in danger, they're not going to get raped, they're not going to get beaten. So I don't want to minimize that because those are very valuable investigations, but we do focus more on female victims and there's some female victims in forced labour as well, but we do look at those, but it's not as high priority as female victims in the sex trade.

The beliefs and priority given to the issue of human trafficking for sexual exploitation thus contributes directly to lower action on labour trafficking by law enforcement authorities, which in turn propels forward the idea that labour trafficking constitutes a very small proportion of the overall trafficking problem (Feingold, 2010; Hastie, 2012; Thompson, 2006).

Despite such perceptions that labour trafficking represents a small proportion of the overall "trafficking problem" in Canada, a number of cases have surfaced that demonstrate the existence of labour trafficking and illustrate the challenges associated with applying the Criminal Code offence in this context. A small number of labour trafficking cases have proceeded through the criminal justice system in Canada. Recently, two cases of alleged domestic servitude were prosecuted under the IRPA offence of human trafficking; while one case resulted in a conviction by jury trial ( $R v$. Orr), the other resulted in an acquittal ( $R$ v. Ladha). Under the Crimi- 
nal Code, one case of labour trafficking has resulted in a successful conviction to date (R. v. Domotor). This case involved a large-scale organized crime operation, widespread criminal and fraud schemes, and use of significant violence. The accused persons in this case pled guilty to various charges, including, for some, charges of human trafficking ( $R$. v. Domotor).

A number of other cases that have not proceeded to trial have also been identified. ${ }^{13}$ A 2008 case in Elmvale, Ontario involved the deceptive recruitment of men from the Philippines who were forced to work and live in poor conditions, had their identity documents and wages withheld, and movement controlled (Brazao, 2008). This case presented numerous indicators of labour trafficking, as understood under international law; however, this case was not perceived to fall within the prescribed definition of exploitation under the Criminal Code because the men did not appear to fear for their safety (Brazao, 2008). In 2011, a group of labourers in the agricultural industry in Windsor, Ontario were recognized by Citizenship and Immigration Canada as trafficked persons, and allowed to remain in the country to pursue private legal remedies, despite the fact that no criminal charges were laid in that case (LaJoie, 2011). The case presented similar features to that of the Elmvale case: poor living and working conditions; withholding of wages; and, the deduction from wage payment for inflated living costs as well as penalties (LaJoie, 2011). As will be explored further in the following sections, the nonphysical and non-violent nature of the conditions have resulted in difficulty in determining whether the situation falls within the legal understanding of "human trafficking" under Canadian criminal law.

More recently, in 2012, a case involving $60 \mathrm{mi}$ grant workers from Poland and the Ukraine surfaced in St. Paul, Alberta. Three individuals were initially charged with human trafficking for allegedly exploiting the labour of 60 migrants working for their company, Kihew Energy Services Ltd (Alberta Police Report, 2012; Citizenship and Immigration Canada [CIC], 2012). In the end, the company pled guilty to lesser charges of human smuggling (IRPA, s.117) and the human trafficking charges against the individuals were dropped. ${ }^{14}$

\footnotetext{
${ }^{13}$ While these cases are primarily found through newsmedia reports and supported by anecdotal accounts from interview participants, the TRP statistics above provide more concrete evidence of the existence of labour trafficking beyond what can be reported or found in the public domain. See also, Sikka (2013) for further documentation of labour trafficking cases in Canada.

14 Of note, Kihew Energy was fined a sentence of \$215,000. However, investigators in the case estimate the company profited approximately $\$ 1,000,000$ by recruiting the Polish workers who arrived on student visas to attend training at Lakeland College. Rather than attending courses, the company sub-contracted the worker's labour at high cost while pay-
}

The offence of human smuggling is very similar to that of human trafficking under IRPA, focusing on organizing entry into Canada in contravention of the Act (in other words, without legal authorization). The only difference between the offences of smuggling and trafficking under IRPA is the use of the means to organize that entry (with trafficking requiring the presence of the means of abduction, fraud, deception or use or threat of force or coercion). Thus, where a case involves a foreign national who entered Canada without proper legal authorization, the human smuggling charges may serve as a complement to trafficking charges where evidence in the case may not be sufficient to meet the burden of proof and elements of the offence. However, because IRPA focuses on unauthorized entry into Canada (both in relation to smuggling and trafficking offences), we contend that it is ultimately of limited value in addressing labour trafficking in Canada, and human trafficking more broadly, as it will remain contained to only one possible population of trafficked persons.

Despite the growing body of evidence of the existence of labour trafficking in Canada, criminal justice representatives suggest they are hesitant to move forward with criminal charges in these cases, and appear to perceive the Criminal Code legislation as particularly problematic in this regard. The following legal analysis explores the primary tensions experienced to date regarding the meaning and applicability of the Criminal Code offence of trafficking in persons, particularly for cases involving non-sexual forms of labour trafficking. This analysis points more broadly to the limitations of responses dominated by a criminal law framework.

\section{Interpreting the Criminal Code Offence of Trafficking in Persons: Pitfalls and Possibilities}

This section engages in a legal analysis of the Criminal Code offence of trafficking in persons, in order to better understand both current and possible future interpretations of its requisite elements. The offence of trafficking in persons is set out under sections 279.01 and 279.04 as follows:

279.01 (1) Every person who recruits, transports, transfers, receives, holds, conceals or harbours a person, or exercises control, direction or influence over the movements of a person, for the purpose of exploiting them or facilitating their exploitation is guilty of an indictable offence and liable to imprisonment for life if they kidnap, commit an aggravated assault or aggravated sexual assault against, or cause death to, the victim during the

ing the workers substantially lower rates. The workers were also allegedly instructed not to inform anyone about their low wages and that any breach of contract would result in deportation (Alberta Police Report, 2012). 
commission of the offence; or to imprisonment for a term of not more than fourteen years in any other case.

(2) No consent to the activity that forms the subject-matter of a charge under subsection (1) is valid.

279.04 (1) For the purposes of sections 279.01 to 279.03, a person exploits another person if they cause them to provide, or offer to provide, labour or a service by engaging in conduct that, in all the circumstances, could reasonably be expected to cause the other person to believe that their safety or the safety of a person known to them would be threatened if they failed to provide, or offer to provide, the labour or service;

(2) In determining whether an accused exploits another person under subsection (1), the Court may consider, among other factors, whether the accused used or threatened to use force or another form of coercion; used deception; or abused a position of trust, power or authority. ${ }^{15}$

The wording of the offence poses two primary issues to be explored: first, the interpretation and understanding of the acts, under s.279.01, which constitute human trafficking, and specifically whether movement is required as a part of the offence; and, second, the interpretation of scope of the definition of "exploitation", and specifically of the term "fear for safety", under s.279.04.

The Criminal Code sets out the "basic" acts listed under the international Protocol (recruits, transports, transfers, receives, holds, conceals or harbours), as well as the additional acts of "exercising control, direction or influence over the movements of a person". These form the actus reus element of the Criminal Code offence. The listed acts under the offence thus appear quite broad in nature. While the listed acts taken from the Protocol have not been subject to additional interpretation, the acts of "exercising control, direction or influence" were adopted from the language of the procurement offence under the Criminal Code and have been interpreted in case law in that regard. Control has been interpreted to refer to invasive behaviour which leaves little choice to the person controlled; direction has been interpreted to constitute the existence of rules or imposed behaviours; and, influence has been interpreted to include any action done with a view to aiding, abetting, or compelling a person (R. v. Perrault, considering s.212; see also, Roots, 2013). This interpretation of "exercising control, direc-

${ }^{15}$ Subsection (2) to s.279.04 added by amendment: SC 2012 , c15. tion or influence" was adopted in the first trial decision interpreting s.279.01 of the Criminal Code (R. v. Urizar).

Despite the breadth and apparent clarity of the acts listed under s.279.01, their interpretation and application continue to confound criminal justice authorities grappling with cases of human trafficking. A key interpretational challenge expressed by criminal justice authorities and service providers is the question of whether movement of some kind is required as an element of the offence, mirroring similar confusion at the international level (Gallagher, 2010). Although the list of associated acts under s.279.01 is disjunctive, and thus implies that movement may not be required as an element of the crime, some criminal justice authorities interpret this as a mandatory element. ${ }^{16}$ As one legal representative commented:

I think if you read within the context of the of the definition there, the person who's charged doesn't have to be solely responsible for the movement; they can facilitate it, they can counsel it, they can assist, but ultimately there has to be a movement of a person and then the servitude of the exploitation.

Similarly, in applying the legislation, some law enforcement officials rely on the element of movement as the defining factor for determining whether to lay human trafficking charges. As one law enforcement representative indicates:

I had a file where someone thought she was just going be working as like a stripper, or a dancer at bachelor parties and she got mentally forced into doing prostitution as well, which wasn't her main goal but then she just kept getting hounded and hounded and hounded so much that she definitely did stay in it because she felt forced to. However, that doesn't fall under human trafficking because she wasn't taken anywhere but she was forced to work in the sex trade, which is stuff we do prosecute and we see that more often (emphasis added).

As this excerpt suggests, movement is sometimes perceived in the field as the primary distinguishing factor used to determine whether a case falls under the trafficking in persons legislation versus pursuing charges under a related section of the Criminal Code. While there is greater availability of options for alternate

\footnotetext{
${ }^{16}$ Of the dozen cases with convictions secured under s.279.01.04 in Canada to date, 11 of these involved domestic sex trafficking, meaning that the trafficked persons were not moved across international borders. While some cases involved transport between cities, others appeared to be rooted within one area. See, generally, UNODC (2013); RCMP (2010). While the Criminal Code language appears not to require movement, clearly this is an interpretive issue which causes confusion and a hesitance to use the offence in practice.
} 
charges in relation to a potential case of trafficking for sexual exploitation, as discussed in the Introduction, options of alternate charges in cases of labour trafficking are very limited.

In addition to the confusion surrounding movement, the wording of s.279.01 states that the accused must engage in conduct "for the purpose of exploiting them or facilitating their exploitation", which forms the mens rea element of the offence. However, this component of the offence must be interpreted in light of the definition of exploitation found under s.279.04. In interpreting this element of the criminal offence, it may appear that the Criminal Code does not require a "means" element as found under the Protocol, and that this definition of "exploitation" correlates to the purpose of exploitation under the Protocol's 3-pronged definition. However, as the subsequent analysis will demonstrate, the definition of exploitation under s.279.04 in fact imports an implicit means element in understanding what is meant by "fear for safety", and the fact that this is not explicit and in line with the Protocol has only added to confusion at the interpretive and implementation levels.

Establishing exploitation requires that the accused engaged in conduct that "in all the circumstances, could reasonably be expected to cause the other person" to fear for their safety (Criminal Code, s.279.04, emphasis added).This language also appears in the Criminal Code offence of criminal harassment, which will thus be used as a starting point for analysis. In this context, reasonableness requires an objective foundation, based upon an ordinary reasonable person's view; but can also account for the particularities of the victimized individual's circumstances, such as age, gender, and vulnerabilities (R. v. Sillip, paras. 25-27). The test, as it relates to criminal harassment, and applicable here, has been put as this: "[i]n order to determine whether her fear was reasonable we must look at the events as set out above objectively in the context of all the events and having regard to the person to whom the words were addressed" (R. v. Haroon, para. 66). Thus, the test requires both an objective (reasonable person) and subjective (particular circumstances of this case and this victim) element. It is not necessary to prove actual fear by this victim; the offence rather requires evidence that it would be reasonable for a person, with a similar background to and in similar circumstances as the victim, to be fearful. As regards the interpretation of "safety", this language has been interpreted in criminal harassment case law to include not just physical harm, but also psychological safety (R. v. Sillip, 418-19, aff'd in R. v. Ryback, R. v. Goodwin). ${ }^{17}$

17 See also, $R$ v. Hau (1996, para. 73); $R$ v. Gowing (1994); $R v$. McCraw (1991) (interpreting "serious bodily harm" to include psychological integrity, health or well-being); $R v$. Haroon (2011); R v. Bachmaier (2009).
While it is concretely recognized that, in the context of criminal harassment, safety includes the concepts of psychological and emotional security, its translation beyond that context, and specifically to the concept of human trafficking, remains uncertain. Criminal harassment by its very nature connotes an understanding of activity that is deliberately used as a "tool of intimidation" (R. v. Haroon, 2011). While some of the requisite means of human trafficking under the Protocol also imply intimidation (such as coercion, threats, and abuse of a position of power), others do not (such as fraud, deception, and, in some circumstances, abuse of a position of vulnerability). Thus, human trafficking, at the international level, seeks to criminalize a broader range of conduct beyond "intimidation" as set out in the criminal harassment offence. The offence of criminal harassment also criminalizes conduct that rises to a particularly egregious level, such that the very consequence of the conduct is reasonably seen to be a fear for one's safetywhether physical, psychological, or emotional, whereas the concept of human trafficking, as outlined in the international Protocol, criminalizes conduct where the natural consequence of those means does not necessarily imply that a person will fear for his or her safety or security (Protocol, art.3(b); UNODC, 2009; UNODC, 2012). Particularly as concerns labour exploitation, common indicators put forth by the International Labour Organization establish many "targets" of coercive conduct that do not directly relate to the physical safety or security of a person, including restriction of movement, debt bondage, withholding wages, retention of identity documents, and threats of denunciation to authorities (International Labour Organization [ILO], 2005). Finally, although the criminal harassment case law has broadened the interpretation of safety, it could be argued that any psychological or emotional fear is predicated on a fear of the harassment activity rising to a level where bodily integrity or safety will be jeopardized. Thus, its value in advancing a broader understanding of "fear for safety" under the trafficking in persons offence is debatable.

Despite the broader interpretation of this standard outside the context of human trafficking cases, the use of the word "safety" creates a strong connotation that only conduct involving physical force or threats thereof will be considered sufficient to constitute human trafficking under the Criminal Code offence. This interpretation of the standard is supported by evidence from the legislature, law enforcement, and judicial authorities. In the records of the parliamentary committee reviewing the initial bill, the connection between "safety" and physical harm was noted, though not subject to substantial debate: "[b]asically, they fear for their life or physical harm to themselves, or, in the trafficking situation, threats against family members back home" (Senate of Cana- 
da, 2005, emphasis added). In addition, as discussed earlier, in an early case of possible human trafficking known as the "Elmvale 11", the RCMP has also interpreted the "fear for safety" requirement in a narrow manner (Brazao, 2008). The RCMP in that case declined to press charges of human trafficking because the group did not "fear for their safety", despite the fact that the group was subjected to many control mechanisms, including confiscation of documents, isolation, and threats of economic penalties (Brazao, 2008). Finally, in a criminal case involving the trafficking and sexual exploitation of two minors, the accused avoided charges of human trafficking in relation to one of the alleged victims because she did not "fear for her safety", despite the fact that the trafficker used psychological manipulation in order to gain compliance to exploitation (R. v. Nakpangi).

This interpretation and narrow understanding of what human trafficking "looks like" is also supported by evidence from the field. In a quote from a British Columbia law enforcement officer, set out in section 2 of this article, the importance placed on physical violence is extremely evident:

Twenty men from Mexico or Africa who are forced against their will to work under horrible conditions is very, very bad, but you know their lives probably aren't in danger, they're not going to get raped, they're not going to get beaten.

Beyond the gendered assumptions underlying this statement, legitimate confusion appears to exist about what kinds of means or control tactics are sufficient to fall within the scope of this offence. The following excerpt from a law enforcement representative discusses this challenge of applying the law to labour trafficking cases:

Every work related file that I have seen has elements of exploitation. Whether it goes to the code definition of trafficking, perhaps not....Like, are they exploited? They are not bound and gagged and locked in a room and not fed and no passport, etc.

As the above excerpt suggests, enforcement officials' uncertainty about the necessity of physical harm further limits the application of the offence in situations where fraud, withholding wages, or other forms of control or exploitation occur.

This narrow interpretation of directly connecting a "fear for safety" to physical violence or harm is especially restrictive for cases of non-sexual labour trafficking because the use of physical violence has been suggested as a "last resort" in these cases (Coster van Voorhout, 2007) with the availability of other coercive targets-namely economic penalties and threats against administrative status (see also, Kim, 2011). Given the way in which the Criminal Code offence has been written, and is being interpreted, it is arguable, for example, that it would not capture a situation of debt bondage, which is widely accepted as indentured servitude and yet does not require the use or threat of physical violence. ${ }^{18}$ The current wording and interpretation of the "fear for safety" standard under the Criminal Code is too narrow, has resulted in significant confusion in practice about what kind of conduct gives rise to a charge of human trafficking, and potentially fails to capture any non-physical forms of coercion or force.

Although the Criminal Code offence was recently amended to provide added detail to the conduct which can be captured by s.279.04, including: use or threat of use of force or another form of coercion; use of deception; or, abuse of a position of trust, power or authority (s.279.04(2), as amended by SC 2012, c15), these listed means will, too, require interpretation to determine the scope of their applicability. Further, these additional enumerated factors must still be read in light of the definition of "exploitation" and concept of "fear for safety" under s.279.04; thus, their utility in improving the wording and application of the Criminal Code offence is questionable.

\section{Implementing the Criminal Code Offence of Trafficking in Persons: Evidentiary Burdens}

Criminal justice authorities cite numerous obstacles to successful implementation of the Criminal Code offence, including evidentiary burdens and dependency on the cooperation of the trafficked persons. In addition to confusion surrounding the interpretation of the Criminal Code wording, the offence as structured under s.279.04 has created a situation where victim cooperation, testimony, and credibility are perceived as the core determinants of possible trial success. As one law enforcement representative has noted: "in a human trafficking investigation, law enforcement's strongest evidence is the victim, so that's a challenge, the biggest challenge". Although this is a challenge common to criminal trials, for cases of human trafficking, victim cooperation and credibility can be additionally compounded by issues such as precarious immigration status, fear of authorities, and a lack of physical evidence, to name a few. ${ }^{19}$ Thus, while challenges surrounding victim cooperation and credibility

\footnotetext{
${ }_{18}$ See the UN Supplementary Convention on the Abolition of Slavery, Slave Trade and Institutions and Practices Similar to Slavery, ESC 608(XXI), OHCHR, 1956, Art. 1(a) for the accepted international definition of "debt bondage".

${ }^{19}$ See also, Hanley, Oxman-Martinez, Lacroix, \& Sigalit (2006); $R v$. Ladha where credibility of the alleged victim appeared central to the judicial reasoning and outcome of the case.
} 
are not uncommon, they are often exacerbated in cases of human trafficking. This points to the importance of developing strategies to address trafficking that are not limited to or dependent on a criminal law framework alongside addressing the limitations of evidentiary burdens in the Canadian Criminal Code.

The evidentiary burden under the current trafficking in persons offence is significantly weighted towards evidence and proof that relies on the individual complainant (or, "victim" of crime). Although the wording of the Criminal Code maintains a link between the conduct of the accused and intent, the structure of the offence, and particularly the definition of exploitation, look primarily to the effects on the trafficked person to assess intent. Rather than looking to the conduct of the accused, and the intent behind that conduct, establishing the crime rests heavily on proof that the alleged victim did, or could have reasonably, feared for their safety. This is problematic in that it disproportionately weighs the evidence and credibility of the alleged victim to establish the crime. Further, focusing on the impact to the victim necessarily leaves open the possibility that some indicia of consent by the victim establishes a lack of fear for their safety. Where a victim may have appeared to provide consent, this could be interpreted as establishing a lack of fear for safety.

This confusion and tension regarding the role of consent in the definition of exploitation has been found to exist in practice, and has resulted in perceived difficulties in applying the offence:

You have to prove a fear, you have to prove that [trafficked persons] were entirely unwilling or there was no real consent component at any point, or maybe if there was consent it's a clear delineation of when that consent stopped, and it's just unbelievably onerous. And it may continue to be until we either get charges and the case law defines it, or Parliament realizes that and starts clipping at it. [F]or us, there's two thresholds: one, do we have the grounds to charge and then the threshold to actually convict (as cited in Kaye et al., 2014, p. 13).

As the excerpt above suggests, some law enforcement authorities interpret the current Criminal Code wording as impliedly importing consent as an issue to be proved. This points to the significant weight attributed to indicia of consent in determining whether charges of human trafficking will be successful, substantiating the earlier claims regarding the overemphasis on the impact to the victim in establishing the crime.

Compounding the problematic connection made between consent and exploitation in interpreting the offence, the evidentiary burden for criminal justice authorities is perceived to be heavily reliant on victim cooperation and testimony. As one law enforcement representative suggests:
But essentially that evidence, when a victim testifies and can testify to that brutality and anything, nothing can beat that in terms of evidence. And once you don't have that and have to rely on other evidence then it's weaker. Unless you have a wiretap or whatever, have something like a conversation describing the control, the money, taking the money and all that. So there is various ways of gathering the evidence, it's not like seizing a kilo of coke, just put it evidence and bring a picture to court. You're dealing with a human being there, and that's what makes it a lot more challenging.

Issues of victim cooperation and testimony are not unique to cases of human trafficking; however, given the weight attributed to victim testimony, necessitated by the wording of the Criminal Code offence, the potential gravity of the experience of trafficked persons, and the additional contextual challenges which may exist, overcoming this obstacle does present unique challenges in these cases. In addition, given the nature of the crime of human trafficking, accompanying physical evidence would be rare, as the above excerpt mentions. Thus, trafficking cases may often rest solely on the issue of credibility and competing stories of a trafficked person and accused. Although, again, this is not an issue necessarily unique to human trafficking cases, it is nonetheless an important factor in understanding the problems associated with successful criminal justice responses to the issue, and in exploring the applicability of the offence in non-sexual labour cases.

Some trafficked persons will have been subjected to serious threats and coercion, and may have a fear of authorities instilled in them. Others consider the risks associated with reporting and cooperating with criminal justice authorities to outweigh the potential benefits: "So if they will complain, then the huge possibility of being out of a job is just so huge that they can't have that...they don't want to come out, no matter how much we tell them" (Frontline Service Provider). Fear of participating in criminal justice proceedings is particularly apparent in cases involving foreign nationals in situations of labour exploitation. In such cases, methods of exploitation can cause individuals to fall outside of regular immigration status, creating significant risks in reporting to criminal justice authorities. Describing this type manipulation, one law enforcement representative indicates, "they come for a job, the job doesn't exist. 'Okay go here, you know you are now working without a permit, we are going to tell immigration if you stop'”. ${ }^{20}$ As these excerpts suggest, fear of job loss, deportation, or retaliation are key obstacles for trafficked individuals (as well as individuals facing other forms of exploitation) to report their experiences to the authorities and to participate in crimi-

${ }^{20}$ See also, Hanley et al. (2006) 
nal justice proceedings. In the words of another law enforcement representative:

So they are in violation, they are working without a permit, and they can be removed from the country. So they are working at [fast food restaurant] for longer hours and less pay than everybody else. And so it will be within the fast food industry: "I need a body here, don't tell immigration, we will get the paper work for you and get it sorted out, it's fine". So sort of the same [type of work] but within that industry itself. The exploitation happens and a lot of head offices don't know it's going on. [As soon as they are in violation of the Act] they can be deported and removed, just by working in some place you are not supposed to be working: "we'll tell immigration if you don't [comply]".

Alongside concerns of job security and immigration status, trafficked persons might also give up some available protections for the sake of anonymity. As one service provider explains:

[Fear] of being deported, fear of police and authority. I mean, they claim they would never deport anyone in that case, but we've heard lots of stories of people being deported. It just makes people nervous...[the person] could tell the whole story and then they could say, "oh we don't think that's trafficking", which is what we have had happen before...they were actively talking about what defines trafficking and they were saying, "well we don't know what the intent was...was there intent to sell [the person] before they crossed the border or did they decide after?" And that was their criteria for deciding if it was trafficking.

This excerpt further points to a perceived lack of clarity in criminal justice interpretations of the trafficking in persons offence. Similarly, a former law enforcement representative indicates: "I know personally for myself, I am responsible for removing dozens upon dozens of people that were victims of trafficking and we dealt with them as immigration violators and removed them." Yet even where authorities are able to connect with and provide protection to a trafficked person, obtaining agreement to testify creates additional barriers, given the adversarial nature of criminal proceedings, where the credibility of the trafficked person will likely be "attacked" in court:

And even then when the victim agrees to cooperate and testify, you know the defence, the biggest thing will be the credibility of the victim, the defence will go after their credibility so we have to deal with this. So it makes it challenging.
Given the nature of human trafficking, the very idea of relaying this experience in court and being challenged based on character, can prove a daunting obstacle to overcome.

The risks associated with challenges to credibility, particularly, relate back to the problematic emphasis placed on consent, both in doctrine and in practice. The current confusion and misunderstanding associated with this element of the crime and its interpretation can further undermine the testimony and credibility of a trafficked person where it should not be so. Discussing why human trafficking charges were dropped in an alleged case of trafficking for sexual exploitation, one Crown Prosecutor indicates:

It wouldn't be believed that these women didn't know what they were coming to do and while they were here, they were involved in the sex trade. It was strictly was a case where the charges for living on the avails, which is a case that's still before the courts, was the appropriate charge or really gravity of the offence that we're trying to capture and the human trafficking was an over charge...particularly the definition of exploitation under $\mathbf{2 7 9 . 0 4}$ where we wouldn't have realistically had a prospect of conviction based on that. So it wasn't that we were gun shy to do it, but the evidence has to be there.

Regardless of whether sex trafficking actually took place in this particular case, the excerpt points more broadly to the problematic notion of consent that continues to shape the national response. In particular, knowledge of the work or services to be performed (whether sexual and/or non-sexual) does not negate the possibility that the situation could be one of human trafficking. ${ }^{21}$ However, the authorities in this case did not proceed with trafficking charges given the alleged victims' prior knowledge of the type of services to be offered and the perceived credibility issues they would have at trial. Although this excerpt relates to a case concerning sex trafficking, many similar challenges potentially arise for persons trafficked for non-sexual labour exploitation, since, irrespective of the sector, labourers often have prior knowledge of the work or services to be performed. In many situations, it is the conditions of the work or services being performed which amount to exploitation, rather than the nature of the work or services. Thus, the

\footnotetext{
${ }^{21}$ Although cases of human trafficking can arise through deception or fraud, such that the trafficked person would not have knowledge of the work or services to be performed, cases can also arise where the individual did have this knowledge, but did not have accurate knowledge of the conditions of work, or does not believe he/she has the freedom to leave or refuse the work.
} 
practical obstacles to accessing the necessary testimony and cooperation from a trafficked person compound the limitations already present in the Criminal Code wording, which places significant weight on evidence that must come from the trafficked individual.

\section{Conclusion}

This article sought to investigate the current problems associated with the Canadian Criminal Code offence of trafficking in persons. Many of the doctrinal pitfalls are mirrored in current understanding and practice by justice authorities; yet, as demonstrated, the wording of the offence can be interpreted in a variety of manners. While the "fear for safety" requirement has, for example, proved narrow in its current interpretation and applicability, additional training and literature on this standard could advance an alternative understanding which is capable of encompassing the broad range of conduct that can be used to induce and maintain a person in a situation of human trafficking. Further, while issues relating to the understanding of consent in this context continue to shape criminal justice responses, more realistic understandings of the physical and/or psychological context of trafficked persons may assist authorities in evaluating cases of possible human trafficking. However, the greatest challenge is the fact that the Criminal Code framework remains largely untested. This is both a substantial cause and effect of the narrow understandings and interpretations of the crime. Caught in this cycle, the future of the Criminal Code framework remains uncertain and tenuous in its ability to effectively respond to human trafficking in Canada.

Given the limitations in the wording and interpretation of the Criminal Code offence and the evidentiary burdens associated with the offence, the trafficking in persons legislation has created a "catch-22" for law enforcement, but also for trafficked persons. For law enforcement, investigators rely on alternate or complementary charges rather than human trafficking charges under the Criminal Code definition. Such reliance on alternate measures occurs regardless of whether investigators perceive the cases as instances of human trafficking. In doing so, the Criminal Code definition remains relatively untested, particularly as it applies to labour trafficking cases, which further restricts its applicability to such cases. The existing trafficking in persons legislation has also created a "catch-22" for trafficked persons who not only experience various forms of exploitation, but also face substantial risks in reporting their experiences or cooperating with law enforcement officials, including possible disciplinary action, such as deportation. Where enforcement officials continue to rely on alternate charges, trafficked individuals may be left without any effective legal redress. This is especially evident in alleged cases of la- bour trafficking because the availability of alternate Criminal Code charges are minimal in this context.

Moreover, in a context where enforcement officials are hesitant to pursue human trafficking charges, trafficked persons are further relied upon to assume an unduly burden in criminal proceedings, given both the weight attributed to their testimony, and the significant and numerous "attacks" which can be made against them in establishing their case. In the words of one law enforcement representative, "well I think the main concern tends to be that these are laws that were not written with the victim at the core". The limitations of the Criminal Code offence underscores the need to evaluate the current legal framework and improve responses to human trafficking in Canada.

The article also points broadly to the limitations of relying on a criminal law framework to address trafficking. Thus, any suggestions to revise the legal framework should be considered alongside preventative and intervention strategies that fall outside the rubric of criminalization. For instance, the ILO 2014 Protocol on Forced Labour highlights the need to provide broader strategies of labour inspection and regulation alongside protection for individuals forced to provide labour, regardless of their legal status in the country. However, these considerations should be examined alongside concerns raised by migrant rights advocates that antitrafficking responses are employed to restrict the migratory movements of individuals in a context of global economic inequality (see, for example, Kapur, 2003; Lee, 2011; Sassen, 2002). Nonetheless, the ILO Protocol also highlights the importance of criminal offences and ensuring the offences are adequate and enforced. Thus, broader models of response should be considered alongside addressing the limitations of the Canadian Criminal Code. In the meantime, for individuals subjected to labour trafficking, the current framework and its interpretation will continue to prove problematic.

\section{Acknowledgements}

Dr. Kaye acknowledges support from the Social Sciences and Humanities Research Council of Canada (SSHRC).

\section{Conflict of Interests}

The authors declare no conflict of interests.

\section{References}

Alberta Police Report. (2012). Conviction obtained in human trafficking and human smuggling investigation. Alberta, Canada: Alberta Police Report.

Bill C-310, An Act to Amend the Criminal Code (Trafficking in Persons) $20121^{\text {st }}$ Session, 41 ${ }^{\text {st }}$ Parliament, SC 2012, c. 15. 
Brazao, D. (2008, August 20). Exploited workers' Canada's "slave trade". The Toronto Star. Retrieved from www.thestar.com

Chapkis, W. (2004). Soft glove, punishing fist. In E. Bernstein, \& L. Schaffner (Eds.), Regulating sex: The politics of intimacy and identity (pp. 51-65). New York: Routledge.

Citizenship and Immigration Canada. (2012, October 10). Statement-Ministers Kenney and Toews Commend law enforcement for convictions in human trafficking case.

Coroners and Justice Act 2009 c.25.

Coster van Voorhout, J. E. B. (2007). Human trafficking for labour exploitation: Interpreting the crime. Utrecht Law Review, 3(2), 44-69.

Crimes Legislation Amendment (Slavery, Slavery-like Conditions and People Trafficking) Act 2013, No.6.

Criminal Code of Canada, RSC 1985, c C-46.

Doezema, J. (2002). Who gets to choose? Coercion, consent, and the UN Trafficking Protocol. Gender and Development, 10(1), 20-27.

Doezema, J. (2010). Sex slaves and discourse masters: The construction of trafficking. London: Zed Books.

Downe, P. (2006). Two stories of migrant sex work, cross-border movement and violence. Canadian Woman Studies, 25(1-2), 61-66.

Feingold, D. (2010). Trafficking in numbers: The social construction of human trafficking data. In P. Andreas (Ed.), Sex, drugs and body counts: The politics of numbers in global crime and conflict (pp. 46-74). New York: Cornell University Press.

Gallagher, A. (2010). The international law of human trafficking. New York: Cambridge University Press.

Hanley, J., Oxman-Martinez, J., Lacroix, M., \& Sigalit, G. (2006). The "deserving" undocumented? Government and community responses to human trafficking as a labour phenomenon. Labour, Capital \& Society, 39(2), 98-99.

Hastie, B. (2012). Doing Canada's dirty work: A critical analysis of law and policy to address labour exploitation and trafficking. In A. Quayson, \& A. Arhin (Eds.), Labour migration, human trafficking and multinational corporations (pp. 121-137). New York: Routledge.

Hua, J. (2011). Trafficking women's human rights. Minneapolis, Minnesota: University of Minnesota Press.

Hua, J., \& Nigorizawa, H. (2010). US sex trafficking, women's human rights and the politics of representation. International Feminist Journal of Politics, 12(3-4), 401-425.

Immigration and Refugee Protection Act SC 2001, c27.

International Labour Organization. (1932). Convention concerning forced or compuslory labour (1 May 1932, 39 UNTS 612). Geneva: International Labour Organization.

International Labour Organization. (2005). Human trafficking and forced labour exploitation, guidance for legislation and law enforcers. Geneva: International Labour Organization.

Jordan, A. (2002a). The annotated guide to the complete UN Trafficking Protocol. Washington: International Human Rights Law Group.

Jordan, A. (2002b). Human rights or wrongs. Gender and Development, 10, 28-37.

Kapur, R. (2003). The "other" side of globalization: The legal regulation of cross-border movements. Canadian Women Studies, 22, 6-15.

Kaye, J., Winterdyk, J., \& Quarterman, L. (2014). Beyond criminal justice: A case study of responding to human trafficking in Canada. Canadian Journal of Criminology and Criminal Justice, 56(1), 23-48.

Kempadoo, K. (2005). Introduction: From moral panic to global justice. In K. Kempadoo, J. Sanghera, \& B. Pattanaik (Eds.), Trafficking and prostitution reconsidered: New perspectives on migration, sex work, and human rights (pp. vii-xxxiv). London: Paradigm.

Kim, K. (2011). The coercion of trafficked workers. lowa Law Review, 96, 409-474.

LaJoie, D. (2011, June 21). Exploited farm workers win reprieve. The Windsor Star. Retrieved from http://www2.canada.com/windsorstar

Lee, M. (2011). Trafficking and global crime control. Thousand Oaks, CA: SAGE.

Oxman-Martinez, J., Lacroix, M., \& Hanley, J. (2005). Victims of trafficking in persons: Perspectives from the Canadian community sector. Ottawa: Department of Justice.

Public Safety Canada. (2012). National action plan to combat human trafficking. Public Safety Canada. Retrieved from www.publicsafety.gc.ca.

Public Safety Canada. (2013). National Action Plan to combat human trafficking-2012-2013 annual report on progress. Public Safety Canada. Retrieved from www.publicsafety.gc.ca

$R$ v. AA 2012 OJ No 6256 (QL).

$R$ v. Bachmaier 2009 OJ No 5761 (Ont CJ).

$R$ v. Byron 2013 ONSC 6427.

$R$ v. Domotor 2012 OJ No 3630 (QL).

$R$ v. Estrella 2011 OJ No 6616 (QL).

$R$ v. Goodwin 1997 BCCA 269.

$R$ v. Gowing 1994 OJ No 2743 (Ont CJ).

$R$ v. Hau 1996 CarswellBC 1065.

$R$ v. Haroon 2011 CarswellAlta 2555 (Alta Prov Ct).

$R$ v. Ladha 2013 BCSC 2437.

$R$ v. McCraw 19913 SCR 72.

$R$ v. Nakpangi 2008 CarswellOnt 9334 (WL Can) (Ont Ct J).

$R$ v. Ng, 2007 BCPC 204.

$R$ v. Orr 2013 BCSC 1883.

$R$ v. Perrault 1996113 CCC (3d) 573; 1996 CarswellQue 1069.

R v. Sillipp 199599 CCC (3d) 394 (Alta QB), 1995 CanLII 5591 (ABQB).

R v. Sillip 19982 WWR 653, 1997 ABCA 346.

$R$ v. St Vil, 2008 OJ No 6023 (QL). 
$R$ v. Ryback 1996 BCJ No 285.

$R$ v. Urizar 2010 Longueuil 505-01-084654-090 (CQ).

Roots, K. (2013). Trafficking or pimping? An analysis of Canada's human trafficking legislation and its implication. Canadian Journal of Law and Society, 28(1), 21-41.

Royal Canadian Mounted Police. (2010). Human trafficking in Canada: A threat assessment. Ottawa: Royal Canadian Mounted Police.

Royal Canadian Mounted Police. (2013). Summary of trafficking convictions. Royal Canadian Mounted Police Human Trafficking National Coordination Centre. Retrieved from www.rcmp-grc.gc.ca

Sanghera, J. (2005). Unpacking the trafficking discourse. In K. Kempadoo, J. Sanghera, \& B. Pattanaik (Eds.), Trafficking and prostitution reconsidered: New perspectives on migration, sex work, and human rights (pp. 3-24). London: Paradigm Publishers.

Sassen, S. (2002). Women's burden: Counter-geographies of globalization and the feminization of survival. In K. Saunders (Ed.), Feminist post-development thought: Re-thinking modernity, post-colonialism, and representation (pp. 89-104). London, UK: Zed Books.

Senate of Canada. (2005). Proceedings of the Standing Senate Committee on Legal and Constitutional Affairs, 38 ${ }^{\text {th }}$ Parliament, $1^{\text {st }}$ Session, issue no. 25.

Sikka, A. (2013). Labour trafficking in Canada: Indicators, stakeholders, and investigative methods (Report No. 42). Ottawa: Public Safety Canada.

Soderlund, G. (2005). Running from the rescuers: New U.S. crusades against sex trafficking and the rhetoric of abolition. NWSA Journal, 17(3), 4-86.

Strauss, A. \& Corbin, J. (1998). Basics of qualitative research: Techniques and procedures for developing grounded theory (2nd ed.). Thousand Oaks, California: Sage.

Thompson, K. (2006). A summary of challenges facing legal responses to human trafficking for labour exploitation in the OSCE region. Background paper for the Alliance against Trafficking in Persons High-Level Conference, Vienna, Hofburg, Neuer Saal.

Thorbek, S., \& Pattanaik, B. (Eds.). (2002). Transnational Prostitution: Changing patterns in a global context. New York: Zed Books.

United Nations. (1956). UN Supplementary Convention on the Abolition of Slavery, Slave Trade and Institutions and Practices Similar to Slavery (ESC 608(XXI), $\mathrm{OHCHR}$ ). Geneva, Switzerland: United Nations.

United Nations. (2000). Protocol to Prevent, Suppress and Punish Trafficking in Persons, Especially Women and Children (2237 UNTS 319). New York: United Nations.

United Nations Office on Drugs and Crime. (2009). Model law against trafficking in persons. Vienna: United Nations.

United Nations Office on Drugs and Crime. (2012). Abuse of a position of vulnerability and other "means" within the definition of trafficking in persons. Vienna: United Nations.

United Nations Office on Drugs and Crime. (2013). UNODC human trafficking case law database. United Nations Office on Drugs and Crime. Retrieved from http://www.unodc.org/cld/index.jspx.

US State Department. (2010). Trafficking in Persons Report. US State Department. Retrieved from www.state.gov

US State Department. (2011). Trafficking in Persons Report. US State Department. Retrieved from www.state.gov

US State Department. (2012). Trafficking in Persons Report. US State Department. Retrieved from www.state.gov

William Wilberforce Trafficking Victims Protection Reauthorization Act 2008 (H.R.) $7311\left(110^{\text {th }}\right)$.

\section{About the Authors}

\section{Dr. Julie Kaye}

Dr. Julie Kaye is an Assistant Professor of Sociology and Director of Community Engaged Research at The King's University. Her research and current book project examines representations of human trafficking and anti-trafficking responses in Canada. She has led investigations into human trafficking in Alberta and published findings from this research in the Canadian Journal of Criminology and Criminal Justice. She has also published on conflict and peacebuilding in West Africa in journals such as the Journal of Development Studies and the Journal of Contemporary African Studies.

\section{Bethany Hastie}

Bethany Hastie is a doctoral candidate at the Institute of Comparative Law, McGill University. She holds an LL.M. degree from McGill University, and J.D. from the University of British Columbia. 


\section{Appendices}

Appendix A. List of Selected Government and Nongovernment Organizations Represented by Participants in One-onOne Interviews.

\section{National and International}

Royal Canadian Mounted Police

Citizenship and Immigration Canada

Global Alliance against Trafficking in Women (GAATW) Canada

Canadian Council of Refugees (CCR)

United Nations High Commission for Refugees

\section{Alberta}

Action Coalition on Human Trafficking (ACT) Alberta

Street Level Consulting and Counseling

Calgary Catholic Immigration Services

Calgary Immigrant Women's Association

SHIFT Calgary

Calgary Police Services

Calgary Communities against Sexual Assault (CCASA)

Distress Center

Alberta Justice

Chrysalis Network

\section{British Columbia}

Covenant House

MOSAIC

No one is Illegal

British Columbia Office to Combat Trafficking in Persons (BCOCTIP)

Resist Exploitation, Embrace Dignity (REED)

Vancouver Rape Relief

British Colombia Coalition of Experiential Communities (BCCEC)

Providing Alternatives, Counseling and Education (PACE) Society

Vancouver Police Department

Salvation Army

The Future Group

Supporting Women's Alternatives Network (SWAN)

Aboriginal Women's Action Network (AWAN)

FIRST (decriminalize sex work)

\section{Manitoba}

Mamawichiatata Centre

Sage House

Transition, Education and Resources for Females (TERF)

Child and Family Services

Assembly of Manitoba Chiefs

Welcome Place

Winnipeg Police Service

Sexual Exploitation Unit, Province of Manitoba

9 Circles

Ka Ni Kanichihk

Mount Carmel Clinic

Street Connections 
Appendix B. Open-Ended Guide for One-on-One Interviews.

\section{Nongovernment organization employees}

1. From your perspective, what are the experiences of trafficked persons?

2. How does your organization define human trafficking?

3. From your perspective, how does the general public understand the issue of human trafficking?

4. How does your organization address the experiences of trafficked persons?

5. From your perspective, what are the service provision needs of trafficked persons?

6. Are these needs being addressed by current anti-trafficking responses and policies?

7. What challenges have you faced in responding to the experiences of trafficked persons?

8. What successes have you had in addressing the issue of human trafficking?

9. Were trafficked persons consulted in designing your anti-trafficking programs?

10. How do you think Canadian anti-trafficking policies can better address the rights and experiences faced by trafficked persons?

\section{Nongovernment organization employees, policymakers, immigration and law enforcement officials}

1. How has the adoption of legal instruments, such as Section 279 of the Criminal Code and Section 118 of the Immigration and Refugee Protection Act, addressed or failed to address the issue of human trafficking in Canada?

2. How effective has the temporary resident permit (TRP) program been in addressing the experiences of trafficked women?

3. What are the strengths and limitations of the TRP program?

4. Have TRPs improved access to healthcare and basic social services for trafficked persons?

5. Do you think there is adequate cooperation at provincial and federal levels to address the issue of human trafficking in Canada?

6. From your perspective, what are the experiences of trafficked persons?

7. What service provision needs do trafficked individuals have?

8. Are Canadian policies effective in addressing the rights and experiences of trafficked persons?

9. Were you consulted in the development of a national strategy to address human trafficking?

10. What issues would you like to see included in a national strategy to address the issue of human trafficking in Canada? 